\title{
Retraction Note: Mountain air pollution evaluation and tourism brand building based on remote sensing image processing
}

\author{
Mingzhen Zhou ${ }^{1} \cdot$ Hongfen Zuo ${ }^{2} \cdot$ Peihua Xiao ${ }^{3} \cdot$ Xiaoguang Zhang $^{4}$
}

Published online: 30 November 2021

C) Saudi Society for Geosciences 2021

Retraction Note: Arabian Journal of Geosciences (2021) 14: 1851 https://doi.org/10.1007/s12517-021-08159-z

The Editor-in-Chief and the Publisher have retracted this article because the content of this article is nonsensical. The peer review process was not carried out in accordance with the Publisher's peer review policy. The authors have not responded to correspondence regarding this retraction.

The original article can be found online at https://doi.org/10.1007/ s12517-021-08159-z.

\section{Hongfen Zuo}

zuoyanyan1983@163.com

1 School of Humanities, Yantai Nanshan University, Yantai 265713, Shandong, China

2 School of Industry, Yantai Nanshan University, Yantai 265713, Shangdong, China

3 Students' Affairs Division, Yantai Nanshan University, Yantai 265713, Shandong, China

4 Inspection Station, Longxin Monitoring Technology Co. Ltd, Yantai 265713, Shandong, China 